DOI: https://doi.org/10.24127/ajpm.v10i4.4277

\title{
DESIGN RESEARCH : BAHAN AJAR MATEMATIKA BERBASIS VBA EXCEL DENGAN PENDEKATAN ETICA
}

\author{
Linda $^{1}$, Asep Ikin Sugandi ${ }^{2 *}$ \\ 1,2* IKIP Siliwangi, Cimahi, Indonesia \\ *Corresponding author. Jl. Terusan Jend. Sudirman, 40521, Cimahi, Jawa Barat. \\ E-mail: $\quad$ linda1010nda@gmail.com ${ }^{1)}$ \\ $\underline{\text { asepikinsugandi@gmail.com }}^{2 *}$
}

Received 24 September 2021; Received in revised form 02 December 2021; Accepted 22 December 2021

\begin{abstract}
Abstrak
Bahan ajar berbasis VBA Excel ialah cara interaktif untuk menyajikan materi matematika, mempermudah siswa dalam memahami materi bangun ruang sisi lengkung, membuat siswa merasa senang dan termotivasi untuk terus belajar matematika pada masa pembelajaran jarah jauh (PJJ). Sehingga kemampuan berpikir matematis siswa dapat meningkat. Penelitian ini bertujuan untuk mengembangkan bahan ajar VBA Excel pada materi bangun ruang sisi lengkung dengan pendekatan ETICA serta menelaah keefektifan dan kepraktisan dari bahan ajar yang dikembangan menggunakan metode penelitian pengembangan (R\&D) melalui tahap pendahuluan hingga tahap evaluasi formatif. Sampel dalam penelitian ini ialah 10 siswa kelas IX SMP Negeri 32 Bandung (uji terbatas) dan 28 siswa kelas IX-F SMP Negeri 32 Bandung (uji luas), Jawa Barat. Instrumen yang digunakan ialah lembar validasi ahli dan praktisi, tes butir soal tipe uraian sebanyak 7 soal, angket siswa dan wawancara. Hasil penelitian ini menemukan bahwa bahan ajar berbasis VBA Excel dengan pendekatan ETICA memenuhi kriteria kualitas: valid dengan rata-rata sebeser $83 \%$, praktis dengan rata-rata $82,60 \%$, dan efektif dengan rata-rata persentase sebesar $86,11 \%$, sehingga bahan ajar VBA Excel dengan pendekatan ETICA sangat cocok dan kondusif untuk digunakan dalam pembelajaran pada masa PJJ, memperoleh respon positif dari siswa, pembelajaran terkesan menyenangkan, dan dapat meningkatkan prestasi belajar siswa dengan lebih baik.
\end{abstract}

Kata Kunci : Bahan ajar VBA excel 1; pendekatan ETICA 2; PJJ 3.

\begin{abstract}
Teaching materials based on VBA Excel are used in an interactive way to present mathematical material, make it easier for students to understand the curved side space building material, make students feel happy and motivated to continue learning mathematics. So that students' mathematical skills to the learning objectives. This study aims to develop VBA Excel teaching materials on curved side space building materials with a ETICA approach and to examine the effectiveness and practicality of teaching materials developed using research and development $(R \& D)$ methods through the preliminary stage to the formative evaluation stage. The sample in this study was 10 students of class IX SMP Negeri 32 Bandung (limited test) and 28 students of class IX-F SMP Negeri 32 Bandung (broad test), West Java. The instrument used was a test item description type as many as 7 questions, student questionnaires and interviews. The results of this study found that VBA Excel teaching materials with the ETICA approach met the quality criteria: valid with mean is $83 \%$, practice with mean is $82,6 \%$, and effective with is $86,11 \%$. So materials learning based on VBA Excel is very well and condusive to use in learning at PJJ era, get a positive response from students,learning seems fun, and can improve student learning achievement better.
\end{abstract}

Keyword: Teaching materials VBA for excel 1; ETICA 2; PJJ 3

This an open access article under the Creative Commons Attribution 4.0 International License

\section{PENDAHULUAN}

Suatu pelajaran akan lebih bermakna bila proses dan kegiatannya dilakukan dengan efektif dan efisien. Suryani (2021) pengetahuan yang telah dipelajari siswa dapat bermakna jika 
bermanfaat bagi dirinya dan lingkungan sekitarnya. Sehingga menurut Trianto (2014) pembelajaran yang efektif dan efisien tidak hanya tentang konsep, teori dan fakta tetapi dapat diaplikasikan dalam kehidupan sehari-hari. Namun saat ini aktivitas pendidikan sedang berada diambang kemalangan karena adanya penyebaran covid-19, akan tetapi tidak menjadi hambatan untuk para peserta didik dan pendidik dalam melaksanakan kewajiban yakni menuntut ilmu dan terus belajar dengan baik. Dalam hal ini, pemerintah membuat suatu kebijakan untuk melakukan pembelajaran jarak jauh (PJJ). PJJ dilakukan secara daring (online) melalui teknologi, media, atau ICT sebagai penunjang pembelajaran seperti google classroom, zoom meeting, google form, WhatsApp group, dan sebagainya.

Berdasarkan studi pendahuluan yang telah dilaksanakan bahwa banyak siswa yang merasa kesulitan untuk melakukan PJJ. Hal ini disebabkan oleh ketersediaan fasilitas belajar yang siswa miliki di rumah seperti Hp dan kuota, kurangnya perhatian dari orang tua untuk belajar karena orang tuanya bekerja, sehingga berpengaruh terhadap motivasi dan pestasi belajar siswa, serta materi yang disampaikan oleh guru kurang diserap oleh AQ (Adversity Quotient) siswa. Sesuai dengan Hidayat et.al (2018) bahwa AQ akan berpengaruh terhadap pencapaian kemampuan berpikir dan kreativitas siswa. Sehingga menurut Sugandi et.al (2021) kemampuan berpikir siswa masih rendah terutama pada pembelajaran daring, materi yang disajikan tampak abstrak pada pandangan siswa. Hal ini menjadi PR bagi para pendidik (guru) dalam mendesain pembelajaran menjadi lebih baik, menentukan strategi pembelajaran yang digunakan, penyajian materi pembelajaran, serta membuat rancangan pembelajaran yang dapat membuat siswa akan paham terhadap materi yang disampaikan disesuaikan dengan karakteristik siswa, meningkatkan prestasi serta kemampuan siswa dalam pembelajaran matematika. Matematika merupakan mata pelajaran yang penting dalam bidang pendidikan. Menurut Norsanty \& Chairani (2016) dalam mata pelajaran matematika diperlukan adanya peran para pendidik (guru) untuk mengorganisasikan konten materi agar mempermudah para siswa untuk melaksanakan proses pembelajaran (mengaitkan pengetahuan yang baru dengan struktur kognitif yang dimilikinya). Terkhusus siswa SMP materi bangun ruang sisi lengkung.

Materi bangun ruang sisi lengkung sangat penting untuk dipelajari dan dikuasai guna memecahkan masalah yang ada di kehidupan sehari-hari, mengidentifikasi objek berbentuk bangun ruang, mengukur luas permukaan pada bangun, hingga menghitug kapasitas/volume, dengan aturan matematika maka perhitungan yang dilakukan akan testruktur dan proses berpikir matematik siswa akan terus berkembang. Marabesabessy, Hasanah, \& Juandi (2021) mempelajari bangun ruang sisi lengkung merupakan hal yang penting karena siswa bisa menganalisis dan menafsirkan dunia tempat mereka tinggal serta membantu mengoperasikan materi lainnya. Namun, berdasarkan fakta di lapangan menunjukkan bahwa kemampuan berpikir matematis siswa SMP masih rendah terutama dalam memahami materi bangun ruang sisi lengkung, proses pemecahan masalah yang disusun oleh siswa masih kurang sesuai dengan langkah penyelesaian, kurang sesuainya model matematik 
yang digunakan siswa dalam menyelesaikan masalah. Marabesabessy, Hasanah, \& Juandi (2021) masih ada hambatan dan kesalahan yang dijumpai siswa dalam menyelesaikan soal-soal bangun ruang sisi lengkung. Hal ini disebabkan karena kurangnya penggunaan bahan ajar yang mampu mengkonstruksikan pemahaman siswa terhadap materi bangun ruang sisi lengkung yang diajarkan. Sejalan dengan Nurhaeni, Pranata, \& Respati (2019) bahwa kesulitan siswa dalam memahami masalah matematik dapat disebabkan karena kurang maksimalnya penggunaan bahan ajar untuk matematika terutama materi bangun ruang sisi lengkung.

Untuk mengatasi berbagai problematika yang terjadi pada pelaksanaan PJJ dalam pembelajaran matematik, maka diperlukan suatu bahan ajar yang dapat me mbantu siswa dalam memahami materi dengan lebih baik. Bahan ajar interaktif dan inovatif yang bisa digunakan dalam pembelajaran matematik salah satunya bahan ajar berbasis VBA Excel. Menurut Rohaeti, Bernard, \& Primandhika (2019) VBA adalah bahasa pemrograman yang berasal dari Microsoft Excel dengan fungsi matematika pada suatu objek hingga bisa membuat pengguna untuk lebih berlogika dan meningkatkan daya berpikir secara matematis. Linda,et.al (2019) pembelajaran matematika dengan menggunakan bahan ajar berbasis VBA Excel sangat baik untuk dikembangkan karena sangat mendukung motivasi belajar siswa, membuat rasa ingin tahu siswa terhadap materi yang disajikan, mudah menggeneralisasikan model matematik, sehingga memicu tingkat berpikir matematis siswa. Sejalan dengan Prayogi, Praja, \& Raharjo (2019);
Nu'man (2019) penggunaan bahan ajar dapat meningkatkan motivasi siswa dan semangat untuk belajar, siswa merasa senang dan antusias serta dapat mengatasi kesulitan siswa dalam menyelesaikan masalah. Penyelesaian masalah sangat efektif untuk meningkatkan ketuntasan dari hasil belajar siswa (Sari \& Surya, 2017). Hong \& Kim (2016) masalah yang terstruktur membuat siswa mengaitkan pengetahuan matematika dengan kehidupan sehari-hari.

Agar lebih efektif, pembelajaran didesain dengan menggunakan pendekatan ETICA (Exploration, Technology, Interactive, Collaboration, and Activity). Pendekatan ETICA merupakan strategi khusus untuk pembelajaran yang menggunakan ICT dalam kegiatan belajar. Nasution (2021) Pemanfaatan ICT dalam pembelajaran menjadi suatu kebutuhan dan keharusan demi kemajuan, perkembangan dan tuntutan perkembangan zaman yang bisa disajikan sebagai sumber media dalam belajar.

Adanya pengembangan bahan ajar berbasis VBA Excel diharapkan siswa dapat memahami materi matematika, bisa meningkatkan prestasi belajar siswa, sehingga bisa diaplikasikan dalam kehidupan sehari-hari dengan lebih baik. Oleh karena itu, penelitian ini bertujuan untuk mengembangkan bahan ajar berbasis VBA Excel dengan pendekatan ETICA yang dilakukan berdasarkan hasil analisis lembar validasi, angket respon siswa terhadap proses pembelajaran, dan efektif terhadap kemampuan matematis siswa SMP Kelas IX.

\section{METODE PENELITIAN}

Metode penelitian ini menggunakan jenis penelitian desain research and development (R\&D) 
dengan studi pengembangan. Design Research adalah model pengembangan untuk mendesain dan mengembangkan suatu produk dalam pembelajaran, seperti bahan ajar. Produk dalam penelitian desain ini adalah untuk menghasilkan produk berupa bahan ajar yang digunakan untuk menyelesaikan masalah dalam kegiatan pembelajaran atau pendidikan secara empiris. Sampel dalam penelitian ini ialah 10 siswa kelas IX SMP Negeri 32 Bandung (uji terbatas) dan 28 siswa kelas IX-F SMP Negeri 32 Bandung (uji luas), Jawa Barat. Instrumen yang digunakan ialah lembar validasi ahli dan praktisi, tes butir soal tipe uraian sebanyak 7 soal, angket siswa dan wawancara.

Data yang digunakan dalam penelitian ini berupa data kuantitatif dan kualitatif, data kuantitatif diperoleh dari hasil validitas bahan ajar oleh validator, hasil angket respon siswa dan hasil tes belajar siswa agar bahan ajar memiliki ciri berkualitas dan baik digunakan. Kriteria bahan ajar yang baik ialah memiliki aspek valid, praktis, dan efektif. Bahan ajar yang dikembangkan divalidasi oleh 2 ahli yaitu Dr. H. Asep Ikin Sugandi, M.Pd dan Heryanto, S.Kom, satu orang praktisi/guru matematika kelas IX Ibu Lina, S.Pd.

Penilaian pada bahan ajar menurut Torio (2015) meliputi aspek; 1) konstruk (kejelasan petujuk pengerjaan), 2) isi (kebenaran materi, kesesuaian materi dengan kemampuan siswa dan materi disajikan berdasar kontekstual serta mengunggah motivasi belajar siswa), dan 3) bahasa (penggunaan tata bahasa yang baku, bahasa mudah dipahami oleh siswa, kejelasan struktur kalimat).

Penilaian kevalidan dan kepraktisan dengan menggunakan rumus sebagai berikut.

Kevalidan $(\mathrm{V})=\frac{f}{N} \times 100 \%$
Kepraktisan $(\mathrm{P})=\frac{f}{N} \times 100 \%$

dimana :

$\mathrm{V}=$ Nilai hasil uji kevalidan

$\mathrm{P}=$ Nilai hasil uji kepraktisan

$\mathrm{f}=$ Perolehan skor

$\mathrm{N}=$ Skor maksimum

Penilaian validasi bahan ajar dianalisis dengan menggunakan beberapa langkah-langkah sebagai berikut: 1) tabulasi data, 2) perhitungan rata-rata skor, dan 3) konversi skor dengan pedoman menurut Riduwan (2010)

Tabel 1. Pedoman kategori kevalidan dan kepraktisan

\begin{tabular}{ccc}
\hline $\begin{array}{c}\text { Rentang } \\
\text { Skor }\end{array}$ & $\begin{array}{c}\text { Kategori } \\
\text { Kevalidan }\end{array}$ & $\begin{array}{c}\text { Kategori } \\
\text { Kepraktisan }\end{array}$ \\
\hline $81-100 \%$ & Sangat Valid & Sangat Praktis \\
$61-80 \%$ & Valid & Praktis \\
$41-60 \%$ & Cukup Valid & Cukup Praktis \\
$21-40 \%$ & Kurang Valid & Kurang Praktis \\
$0-20 \%$ & Sangat & Sangat Kurang \\
& Kurang Valid & Praktis \\
\hline
\end{tabular}

Penelitian pengembangan dilakukan dengan dua tahap, yaitu tahap pendahuluan dan tahap evaluasi formatif (evaluasi diri, pembuatan prototype, dan uji lapangan). Pada tahap pendahuluan melakukan analisa masalah yang terdapat di lapangan, mewawancarai salah satu guru matematika di SMPN 32 Bandung dan salah satu siswa untuk menemukan masalah dalam pembelajaran. Sedangkan pada tahap evaluasi formatif ini, adanya solusi yang diajukan untuk menyelesaikan masalah yang terjadi di lapangan, dengan merancang, dan mengujicobakan solusi tersebut agar lebih vald dan praktis digunakan. Pada tahap pembuatan prototype dilakukan tiga tahap yaitu; 1) Expert review (review ahli), 2) One-to-one, dan 3) small group (kelompok kecil) (Purwitaningrum \& Prahmana, 2021). 
DOI: https://doi.org/10.24127/ajpm.v10i4.4277

\section{HASIL DAN PEMBAHASAN}

Penelitian pada pengembangan bahan ajar berbasis VBA Excel dengan pendekatan ETICA dilakukan secara terstruktur sesuai dengan metode yang telah dirancang yaitu tahap pendahuluan dan tahap evaluasi formatif. Pembelajaran di desain dengan pendekatan ETICA, dengan karakteristik pendekatan sebagai berikut:

1. Exploration, guru menyajikan konteks/masalah matematik pada bahan ajar sebagai rangsangan awal siswa dalam mencermati, mengidentifikasi serta mengeksplor pengetahuan, ide, gagasan, dan hasil analisa pada masalah tersebut.

2. Technology, pada pelaksanaan kegiatan belajar ditunjang dengan penggunaan teknologi yaitu VBA pada Microsoft Excel.

3. Interactive, adanya jalinan komunikasi antara guru dengan siswa, maupun siswa dengan siswa. Guru memeberi kesempatan kepada siswa untuk bertanya, berpendapat, dan berdiskusi dengan teman sebaya.

4. Collaboration, pembelajaran dilakukan secara berkelompok, dengan aturan guru memberikan tes awal kepada siswa, dan memberikan nilai hasil tes. Kemudian guru membagi 3 kelompok belajar sesuai dengan nilai yang diperoleh siswa, nilai tinggi, sedang, dan rendah, masing-masing kriteria tersebut dipisahkan, siswa yang memperoleh nilai tinggi diberikan soal-soal yang agak sukar, sedangkan siswa yang memperoleh nilai sedang dan rendah diberikan lagi penjelasan materi secara berulang oleh guru. Agar siswa dengan kriteria sedang dan rendah dapat mengejar dan memperoleh pemahaman yang setara, sedangkan siswa yang memperoleh nilai tinggi diberikan soal-soal agar lebih menguasai dan memperdalam skill matematik dengan lebih baik.

5. Activity, setelah materi selesai dipelajari, siswa didorong untuk berlatih menyelesaikan masalah matematik, kemudian dipersentasikan di hadapan temannya, agar melatih keberanian, tanggung jawab, dan rasa percaya diri siswa dalam belajar.

\section{Tahap Pendahuluan}

Pada tahap pendahuluan menetapkan tempat penelitian yaitu di kota Bandung, Jawa Barat. Subjek penelitian untuk uji terbatas yaitu 10 siswa kelas IX SMP Negeri 32 Bandung dan uji luas 28 siswa kelas IX-F SMP Negeri 32 Bandung. Kemudian dilakukan wawancara kepada salah satu guru matematika di SMPN 32 Bandung Ibu Lina, S.Pd dan wali kelas siswa kelas IX-F SMPN 32 Bandung Bapak Aris, S.Pd mengenai efektivitas pembelajaran yang dilakukan selama PJJ. Berikut hasil wawancara yang telah dilakukan pada hari Rabu, 16 Juni 2021 kepada Wali kelas IX-F SMPN 32 Bandung, Bapak Aris, S.Pd mengemukakan bahwa "Pada pelaksanaan PJJ, kegiatan pembelajaran memang agak sulit untuk dilakukan. Selama PJJ pembelajaran dilakukan melalui google classroom dan WA group, hal ini tentu kurang kondusif untuk dilaksanakan karena PJJ ini jadi menghambat komunikasi antara guru dengan siswa, begitupun siswa kurang merespon gurunya dalam pembelajaran".

Dan pada hari Kamis, 17 Juni 2021dilakukan wawancara kepada salah satu praktisi/guru kelas IX SMPN 32 Bandung, Ibu Lina, S.Pd mengemukakan 
bahwa "Selama pelaksanaan PJJ menjadi tantangan bagi guru matematika dalam menyajikan materi, yang mana biasanya materi matematika dijelaskan secara langsung dengan tulisan tangan guru sendiri terhadap siswa, kini berubah pasif hanya melalui google classroom dan sesekali menggunakan zoom meeting itupun jika tidak ada kendala pada siswa. Untuk pembelajaran matematika sendiri belum bisa menggunakan bantuan alat peraga atau media lainnya karena masih menyesuaikan dengan karakeristik siswa dan penguasaan ICT pada gurunya. Namun, kami berusaha untuk terus melaksanakan PJJ pada pembelajaran matematika ini dengan baik."

\section{Tahap Evaluasi Formatif (Evaluasi Diri, Prototipe dan Uji Lapangan)}

Pada tahap evaluasi formatif dilakukan analisis terhadap siswa SMPN 32 Bandung yang mana memiliki kemampuan heterogen (tinggi, sedang, dan rendah). Analisis kurikulum (mata pelajaran matematika kurikulum 2013 didasarkan pada KI dan KD, serta buku yang digunakan dalam pembelajaran terkait materi bangun ruang sisi lengkung. Serta analisis konten (mendesain produk yang akan dikembangkan yaitu bahan ajar berbasis VBA for Excel dengan pendekatan ETICA).

Selanjutnya yaitu pembuatan prototype yang mana perancangan bahan ajar dilakukan dengan prototyping menggunakan tiga karakteristik: isi, konstruksi, dan bahasa. Pembuatan prototipe ini terdiri dari tiga tahap, yaitu: 1) Expert review (review ahli), para ahli pendidikan matematika untuk menilai, mengevaluasi, dan memvalidasi bahan ajar yang telah dirancang untuk melihat kesesuaian dengan karakteristik pendekatan ETICA, bertujuan untuk menguji validitas bahan ajar berdasarkan kriteria yang telah ditetapkan, baik berupa isi, konstruksi, dan bahasa yang digunakan dalam bahan ajar (Prototype I). Berikut rancangan bahan ajar VBA for Excel beserta bahasa program VBA yang digunakan pada materi bangun ruang sisi lengkung untuk siswa kelas IX.

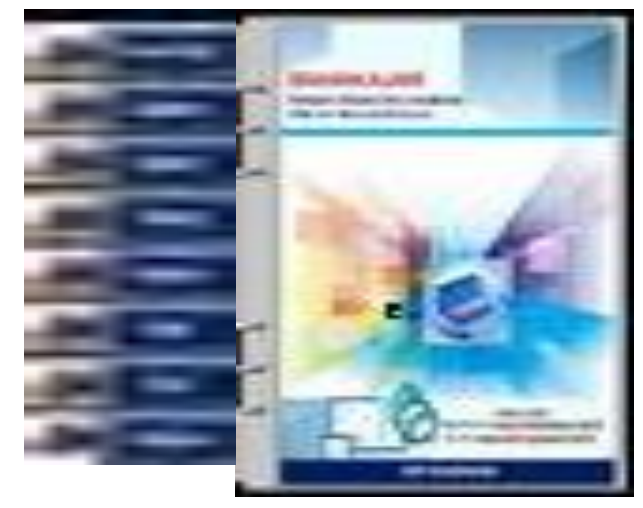

Gambar 1. Prototype bahan ajar VBA excel

Contoh bahasa Program VBA:

Sub panjangkan1()

On Error Resume Next

Dim lembar As Worksheet

Dim lingkar As Shape

Set lembar $=$ Worksheets $(19)$

For j = 1 To Range("b8")

lembar.Shapes("luas" \& j).Delete

Next j

perbesaran = Range("B1")

Range("A9") = Range("A9") + 1

banyak = 360 / Range("A14")

merah $=\operatorname{Rnd}() * 255$

merah $=\operatorname{Rnd}() * 255$

merah $=\operatorname{Rnd}() * 255$

Radius $=2 *$ Range ("B2") * perbesaran

$\mathrm{Pi}=4 * \operatorname{Atn}(1)$

Set lingkar $=$ lembar.Shapes.AddShape (msoShapeArc, 250, 150 - Radius / 2, Radius / 2, Radius / 2)

lingkar.Name = "sisi" \& Range("A9")

lembar.Shapes("sisi" \& Range("A9")).Line.ForeColor.RGB $=\mathrm{RGB}$ (merah, merah, merah)

lembar.Shapes("sisi" \& Range("A9")).Line.Weight = 5 lingkar.Line.EndArrowheadStyle = msoArrowheadNone lingkar.Adjustments.Item(1) = banyak * (Range("A9") - 1) lingkar.Adjustments.Item(2) = banyak * Range("A9")

Range("B9") = Range("B9") + Pi * Radius * banyak / (360

* perbesaran)

Range("D1") = "Keliling = " \& Pi * Radius / perbesaran

End Sub

Sub luasan_11()

On Error Resume Next

Dim lembar As Worksheet

Dim lingkar As Shape

Set lembar $=$ Worksheets $(19)$

perbesaran = Range ("B1")

Range("b8") = Range("b8") + 1

merah $=\operatorname{Rnd}() * 255$

merah $=\operatorname{Rnd}() * 255$ 
DOI: https://doi.org/10.24127/ajpm.v10i4.4277

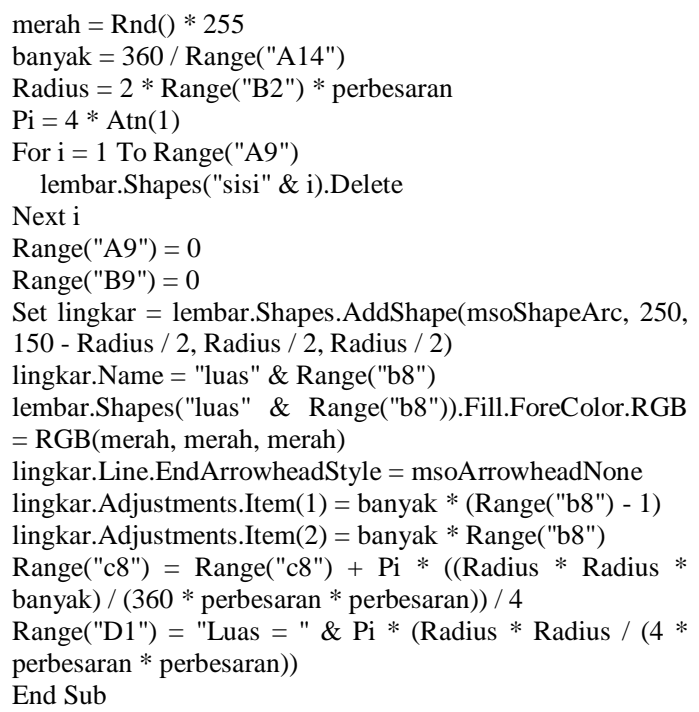

Dari hasil review ahli, bahan ajar direvisi sesuai dengan kritik dan saran yang membangun dari para ahli. Pendapat dan masukan dari pakar (validator) tentang bahan ajar yang telah dirancang dituliskan pada lembar validasi dan kepraktisan sebagai bahan revisi dan pernyataan bahwa bahan ajar tersebut valid dan praktis. Hasil revisi prototipe I pada tahap ini disebut prototipe II. Hasil validasi dari ahli sebelum dan setelah direvisi dapat dilihat pada Tabel 2, sedangkan skor hasil validasi dapat dilihat pada Tabel 3.

Tabel 2. Hasil validasi sebelum dan sesudah revisi

\begin{tabular}{|c|c|}
\hline Sebelum Revisi & Setelah Revisi \\
\hline $\begin{array}{l}\text { 1. Belum adanya petunjuk } \\
\text { untuk peran guru dalam } \\
\text { pembelajaran, pemberian } \\
\text { warna pada setiap tombol } \\
\text { masih terlihat mendung. } \\
\text { 2. Penguatan konsep materi } \\
\text { belum sesuai dengan } \\
\text { kemampuan siswa. } \\
\text { 3. Penggunaan bahasa terlalu } \\
\text { baku dan penulisan pada } \\
\text { caver terlalu besar. }\end{array}$ & $\begin{array}{l}\text { 1. Adanya petunjuk peran guru dan siswa dalam } \\
\text { pembelajaran, dibuatnya peta konsep untuk materi, } \\
\text { Pemberian warna pada setiap tombol kontras dan } \\
\text { design VBA terlihat menarik. } \\
\text { 2. Konsep materi disajikan dengan peragaan pada benda- } \\
\text { benda kontekstual, disesuaikan dengan indikator } \\
\text { pencapaian agar siswa dapat meningkatkan } \\
\text { kemampuan penalarannya, materi disusun mulai dari } \\
\text { mudah, sedang, sukar. Untuk memicu motivasi siswa } \\
\text { dalam belajar. } \\
\text { 3. Menyederhanakan bahasa baku menjadi bahasa } \\
\text { sederhana agar mudah dipahami siswa serta } \\
\text { menyesuaikan ukuran tulisan agar terlihat menarik. }\end{array}$ \\
\hline
\end{tabular}

Tabel 3. Skor dari validator

\begin{tabular}{ccc}
\hline $\begin{array}{c}\text { Aspek } \\
\text { Penilian }\end{array}$ & $\begin{array}{c}\text { Rata-rata } \\
\text { Skor } \\
\text { Validator }\end{array}$ & Kategori \\
\hline Konstruk & $78 \%$ & Valid \\
Isi & $91 \%$ & Sangat Valid \\
Bahasa & $80 \%$ & Valid \\
Rata-rata & $\mathbf{8 3 \%}$ & Sangat Valid \\
\hline
\end{tabular}

Berdasarkan uji validasi pada tabel 3 diperoleh rata-rata validitas $83 \%$ sesuai dengan kriteria rata-rata yang telah ditetapkan maka dapat dikatakan bahwa bahan ajar yang dikembangkan sangat valid. Hal ini berarti bahan ajar yang telah dibuat siap untuk digunakan dalam kegiatan belajar mengajar karena memenuhi kriteria sangat valid. Selanjutnya langkah 2) One-to-one, dimana prototipe II yang dikembangkan diujicobakan pada beberapa siswa secara terpisah satu siswa dan siswa lainnya. Tahapan ini sejajar dengan tahapan review ahli sehingga hasil revisi pada tahap ini digunakan untuk mengedit bahan ajar yang dirancang pada prototipe I untuk menghasilkan prototype II. 3) Small group (kelompok kecil), prototipe II dikembangkan dalam tinjauan ahli, serta melakukan uji terbatas kepada 10 siswa SMP Negeri 32 Bandung yang memiliki kemampuan berbeda (heterogen) untuk mengetahui keefektifan dari bahan ajar, lalu direvisi 
menghasilkan prototipe III. Uji terbatas ini dilakukan pada tanggal 19 Juni 2021 secara daring (online) melalui google classroom. Berikut analisa kepraktisan dari bahan ajar yang dikembangkan dapat disajikan pada Diagram 1.

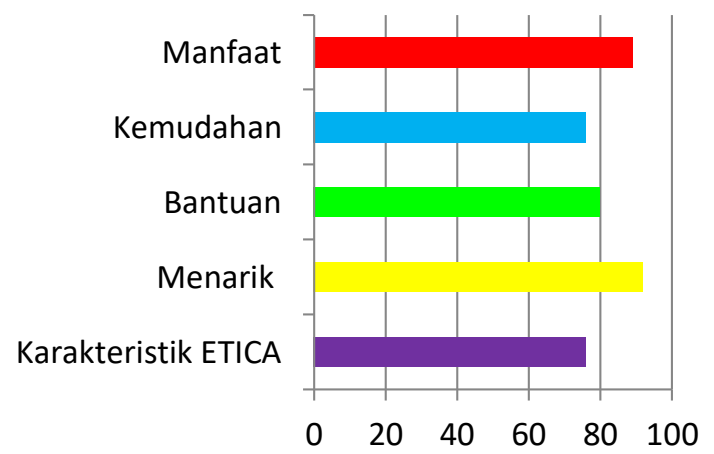

Diagram 1. Hasil kepraktisan bahan ajar

Berdasarkan hasil angket respon siswa pada Tabel 3. Skor dari Validator diperole aspek penilaian pada manfaat sebesar $89 \%$ dengan kategori sangat praktis, aspek kemudahan $76 \%$ kategori praktis, aspek bantuan $80 \%$ kategori praktis, aspek menarik 92\% kategori sangat praktis, dan aspek karakteristik pendekatan ETICA $76 \%$ kategori praktis. Sedangkan rata-rata sebesar $82,6 \%$ dengan kategori sangat praktis sesuai dengan pedoman yang telah ditentukan. Setelah bahan ajar yang dikembangkan memperoleh kriteria valid dan praktis dengan sedikit revisi dari ahli, langkah selanjutnya ialah dilakukan uji lapangan, pelaksanaan penelitian dengan jumlah siswa lebih banyak dibandingkan uji tahap awal yakni pada 28 siswa kelas IX-F di SMP Negeri 32 Bandung, Jawa Barat. Bahan ajar yang diuji pada tahap uji lapangan yakni bahan ajar yang memenuhi kriteria kualitas. Ada tiga kriteria kualitas: valid (dari ahlinya), praktis (mudah digunakan) dan dapat digunakan untuk mengembangkan keterampilan serta kemampuan berpikir matematik siswa (efek potensial). Uji lebih luas ini dilakukan pada tanggal 22-23 Juni 2021 yang mana peneliti bertindak sebagai pengajar dengan menggunakan bahan ajar yang dikembangkan. Untuk hasil belajar siswa, bahan ajar dikatakan efektik jika hasil ketuntasan belajar siswa lebih dari $75 \%$ dan nilai KKM yang ditetapkan oleh sekolah pada mata pelajaran matematika ialah 75 . Berikut rata-rata hasil belajar siswa pada 28 siswa SMPN 32 Bandung disajikan pada diagram 2.

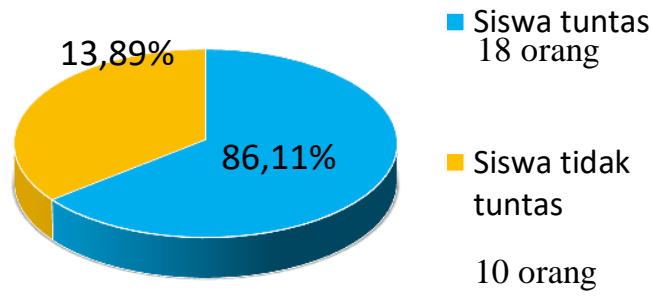

Diagram 2. Persentase Ketuntasan Belajar Siswa

Berdasarkan hasil belajar siswa pada digram 2. dan kriteria ketuntasan menyatakan bahwa seorang siswa dikatakan tuntas jika skor siswa lebih dari nilai KKM yaitu 75. Dengan demikian kriteria keefektifan pembelajaran yang dikembangkan dapat terpenuhi dengan persentase siswa tuntas sebesar $86,11 \%$ sebanyak 18 siswa, yang mana mereka merasa senang dan termotivasi untuk belajar dengan menggunakan bahan ajar yang dikembangkan. Berikut hasil wawancara yang telah dilakukan pada salah satu siswa.

$\begin{array}{rlr}\text { Peneliti : } & \text { Adek, bagaimana } \\ & \text { perasaanmu setelah } \\ & \text { belajar menggunakan } \\ & \text { bahan ajar VBA for } \\ & \text { Excel? }\end{array}$


DOI: https://doi.org/10.24127/ajpm.v10i4.4277

Siswa : Tentu, saya merasa senang dan baru pertama kali ini melihat bahan ajar yang ibu sajikan dalam pembelajaran.

Peneliti : Apakah terdapat perbedaan Antara pembelajaran sebelumnya dan pada saat sekarang?

Siswa : Ada bu, kan biasaanya belajar matematika itu guru hanya menjelaskan saja di papan tulis (waktu luring) namun pada masa PJJ ini guru hanya mengirimkan tugas saja di google classroom dan saya bingung mengerjakannya karena tidak ada penjelasan materi secara langsung. Dan kini belajar dengan bahan ajar saya bisa memahami materi bu,

Peneliti : Apakah kamu merasa tertarik belajar dengan bahan ajar ini?

Siswa : Iya tertarik bu, dan tidak membuat saya mengantuk ketika belajar. Selain itu ada peragaannya juga, jadi saya bisa sambil praktek dan ada teka-teki unik, saya senang sekali bu.

Namun masih ada 10 siswa yang belum tuntas dalam pembelajaran. Setelah dianalisa ternyata beberapa siswa tersebut masih memiliki kesulitan dalam menyelesaikan masalah yang berkaitan dengan bangun ruang sisi lengkung karena kefokusan mereka terbagi pada saat pembelajaran secara daring melalui zoom meeting, terkendala dengan sinyal, jaringan yang tidak stabil, fasilitas kuota kurang memadai, sehingga ketika diberikan butir soal mereka merasa bingung dan ragu dalam menyelesaikannya hingga akhirnya mereka memanfaatkan situasi PJJ ini dengan cara meminta jawaban kepada temannya melalui chat dan sebagainya, agar mereka mendapatkan jawaban instan dari soal yang sulit.

Selain itu, untuk pengumpulan tugas atau hasil tes dikirimkan melalui google classroom. Namun, masih ada beberapa siswa yang terlambat dalam pengirimkan tugas pada waktu yang sudah ditentukan karena fasilitas kuota yang kurang memadai. Oleh karena itu dipilih alternatif lain untuk pengumpulan tugas bisa dikirimkan melalui WhatsApp dan hal tersebut bisa mempermudah siswa. Kendala yang dialami siswa tersebut seperti ayng disajikan pada Gambar 2.

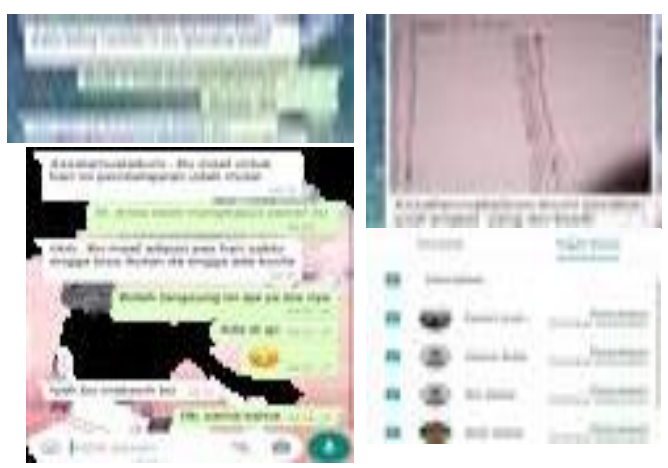

Gambar 2. Kendala siswa pada pelaksanaan PJJ

Hal ini sesuai dengan hasil penelitian yang dilakukan oleh Utami \& Cahyono (2020) bahwa kesulitan belajar siswa ketika pembelajaran daring, yaitu; 1) siswa belum memiliki inisiatif belajar mandiri di rumah, 2) siswa belum terbiasa melaksanakan kebutuhan belajar daring di rumah, 3) sebagian siswa belum bisa memonitor, mengatur dan mengontrol dirinya ketika belajar daring, 4) kurangnya motivasi belajar siswa sehingga siswa mudah menyerah dalam menyelesaikan tugas 
yang diberikan oleh guru, dan 5) siswa jarang melakukan evaluasi proses terhadap hasil belajarnya. Habiba dkk (2020) kesulitan belajar siswa saat pembelajaran daring ialah ketersediaan fasilitas dan jaringan internet yang kurang memadai, pemahaman yang kurang terhadap materi pembelajaran dan suasana belajar di rumah yang kurang kondusif.

Oleh karena itulah, dengan adanya bahan ajar berbasis VBA Excel dapat menjadi solusi dalam pelaksanaan pembelajaran daring yang dapat memudahkan siswa dalam memahami materi, menarik minat dan motivasi belajar siswa, membuat siswa penasaran akan materi yang disajikan pada bahan ajar berbasis VBA Excel. Dengan demikian, prestasi belajar siswa dapat meningkat dan lebih baik.

\section{KESIMPULAN DAN SARAN}

Kesimpulan dari hasil penelitian pengembangan yang telah dilakukan ialah menghasilkan suatu produk bahan ajar yang memiliki kriteria sangat valid, efektif dan sangat praktis. Sehingga bisa terus digunakan dalam kegiatan pembelajaran matematika terutama materi bangun ruang sisi lengkung pada siswa SMP kelas IX. Pengembangan bahan ajar ini memproleh nilai validitas rata-rata sebesar $83 \%$ dengan kriteria sangat valid, rata-rata kepraktisan sebesar $82,6 \%$ kategori snagat praktis, dan persentase rata-rata keefektifan sebesar $86,11 \%$. Serta memperoleh respon positif dari siswa. Untuk lebih meningkatkan kebermanfaatan dari bahan ajar VBA for Excel ini maka peneliti mengajukan saran bahwa bahan ajar VBA Excel dengan pendekatan ETICA ini bisa terus digunakan dalam pembelajaran materi bangun ruang sisi lengkung pada siswa SMP kelas IX pada masa pembelajaran jarak jauh
(PJJ), serta dalam penggunaan bahan ajar ini lebih ditekankan dengan memperhatikan efektivitas waktu, kondisi, karakter dan kemampuan siswa agar bahan ajar yang digunakan sesuai dengan sasaran dan tujuan pencapaian.

\section{DAFTAR PUSTAKA}

Habiba, B., Mulyani, S., Nia N. I., \& Nugroho, P. (2020). Konsep Layanan Responsif Siswa yang Mengalami Kesulitan Belajar secara Daring Dimasa Pandemi Covid-19. Journal of Guidance and Counseling, 4(2). 305-322.

Hidayat, W., Herdiman, I., Aripin, A., Yuliani, A., \& Maya, R. (2018). Adversity Quotient (AQ) dan Penalaran Kreatif Matematis Mahasiswa Calon Guru. Jurnal Elemen, 4(2), 230-242.

Hong, Y. J. \& Kim, K. M. (2016). Mathematical Abstraction. The Solving ill-Structured Problems by elementary School Students in Korea. Eurasia Journal of Mathematics, Science \& Technology Education. 12(2), 267-281.

Linda., Sari, D. R., Fitriani, N., \& Fauziah, P. (2019). Penerapan Pembelajaran Berbasis Etnomatematika Berbantuan VBA for Microsoft Excel terhadap Resiliensi Siswa SMP. Jurnal Pembelajaran Matematika Inovatif, 2(5), 293-300.

Marabesabessy, R., Hasanah, A., \& Juandi, D. (2021). Bangun Ruang Sisi Lengkung dan Permasalahannya dalam Pembelajaran Matematika. EQUALS, 4(1), 1-20.

Nasution, H. D. (2021). Penerapan Media Berbasis ICT (Information and Communication Technologies) dalam 
DOI: https://doi.org/10.24127/ajpm.v10i4.4277

Pembelajaran Matematika di MTs Al-Jam'iyatul Wasliyah Tembung. Prosiding Seminar Nasional Matematika dan Pendidikan Matematika, 6, 373-375.

Norsanty, U.O., \& Chairani, Z. (2016). Pengembangan Lembar Kerja Siswa (LKS) Materi Lingkaran Berbasis Pembelajaran Guided Discovery untuk Siswa SMP Kelas VIII. Jurnal Pendidikan Matematika, 2(1), 12-23.

Nu'man, M. (2019). Development of Teaching Materials of Statistics ff Mathematical Educational Research. Jurnal Mercumatika, 3(2), 114-128.

Nurhaeni., Pranata, O. K., \& Respati, R. (2019). Pengaruh Media Kartu Bilangan terhadap Kemampuan Siswa Mengenai Operasi Pengurangan Bilangan Bulat. Jurnal Ilmiah Pendidikan Guru Sekolah Dasar. 6(1), 58-67.

Prayogi, A. H., Praja, E. S., \& Raharjo, J. F. (2019). Desain Bahan Ajar Bangun Datar Segiempat Berbasis Kemampuan Komunikasi Matematis pada Siswa SMP melalui Model Discovery Learning. LEMMA, 5(2),100-111.

Purwitaningrum, R., \& Prahaman, R.C.I. (2021). Developing Instructional Materials on Mathematic Logical Thinking Through the Indonesian Realistic Mathematics Education Approach. International Journal of Education and Learning, 3(1), 1319.

Riduwan. (2010). Belajar Mudah Penelitian dan Pengembangan. Bandung: Alfabeta

Rohaeti, E.E., Bernard, M., \& Primandhika, R.B. (2019). Developing Interactive Learning Media for School Level
Mathematics Through OpenEnded Approach Aided by Visual Basic Application for Excel. Journal on Mathematics Education, 10(1), 59-68.

Sari, N., \& Surya, E. (2017). Analysis Effectiveness of Using Problem Poshing Model in Mathematical Learning. International Journal of Sciences: Basic and Applied Research (IJSBAR) 13-21.

Siregar, N. C., Rosli, R., \& Maat, S. M. (2019). Development of the DGeometry Module Based on Discovery Learning. International Journal of Academic Research in Progressive Education \& Development. 8(3), 99-109.

Sugandi, A.I., Sofyan, D., Maesaroh, S., Linda., \& Sumarmo, U. (2021). Efektivitas Pendekatan Induktif Deduktif Berbantuan Geogebra terhadap Peningkatan Kemampuan Berpikir Kreatif Siswa pada Masa Pandemi. AKSIOMA, 10(1), 367-376.

Suryani. (2021). Efektifitas Model Pembelajaran Inquiri untuk Meningkatkan Hasil Belajar Siswa Mata Pelajaran IPA di Madrasah Ibtidaiyah Negeri 29 Bireueu. Jurnal Edukasi Matematika dan Sains. 2(1), 5-9

Torio, M.Z.C. (2015). Development of Instructional Material Using Algebra as a Tool in Problem Solving. International Journal of Education and Research, 3(1), 569-586.

Trianto, I. B. A. (2014). Mendesain Model Pembelajaran Inovatif, Progresif, dan Kontekstual. in Prenadamedia Group.

Utami, Y. P., \& Cahyono, D. A. D. (2020). Study at Home: Analisis Kesulitan Belajar Matematika pada Proses Pembelajaran Daring. 
DOI: https://doi.org/10.24127/ajpm.v10i4.4277

\section{Jurnal Ilmiah Matematika}

Realistik, 1(1), 20-26.

Yusepa, B. (2017). Kemampuan

Abstraksi Matematis Siswa

Sekolah Menengah Pertama

(SMP) KLS VIII. Symmetry:

Pasundan Journal of Research in

Mathematics Learning and

Education, 1(1),54-60. 